\title{
Pathology in Focus
}

\section{Plasma cell granuloma of the supraglottic larynx}

\author{
Peter Zbären, M.D.*, Hubert Läng, M.D.†, Karl Beer, M.D.ł, Minerva Becker, M.D.**
}

\begin{abstract}
The occurrence of plasma cell granuloma of the larynx appears to be unusual. Review of the literature revealed only two previously reported cases. We present an additional case of plasma cell granuloma of the larynx. The diagnosis was made by histological and immunohistochemical examinations. The tumour was successfully treated by radiation therapy.
\end{abstract}

Key words: Laryngeal neoplasms; Granuloma, plasma cell

\section{Introduction}

Plasma cells are the secretory form of B-lymphocytes characterized by the presence of abundant proteinsynthesizing equipment in the cytoplasm.

Plasma cell tumours of the head and neck are classified (Batsakis, 1983) as follows: (1) multiple myeloma; (2) solitary plasmacytoma of the bone; (3) extramedullary plasmacytoma (localized or disseminated form); (4) plasma cell granuloma.

Plasma cell granuloma is a rare benign tumour-like lesion affecting people of all ages, found most frequently in the lungs (Bahadori and Liebow, 1973; Mandelbaum et al., 1981; Monzon et al, 1982) and the oral cavity (Warson and Preis, 1969; Batsakis, 1983). Other affected organs have included the abdomen (Issacson et al., 1978; Pisciotto et al., 1978), nasopharynx and maxillary sinus (Guillemin et al., 1989), thyroid (Rockford et al., 1984), mediastium (Hutchins and Eggleston, 1979) and liver (Pack and Baker, 1953). We found only two cases of plasma cell granuloma of the larynx described in the medical literature (Albizzati et al., 1988; Fradis et al., 1988).

We present the clinical and pathological findings of an additional case of plasma cell granuloma of the larynx.

\section{Case report}

A 57-year-old man was admitted with a 10 -month history of dysphagia, hoarseness and a sensation of a lump in his throat. The patient was otherwise healthy with no significant past medical history. He had had no chronic ENT infections. Clinical ENT examination revealed a diffuse submucosal swelling of the epiglottis with extension into the valleculae and right aryepiglottic fold (Figure 1). No regional lymph nodes could be palpated. General physical examination, routine clinical laboratory data and a chest X-ray were normal. MRI examination showed a large tumour originating in the epiglottis with extension to the valleculae and the pre-epiglottic space (Figure 2). Direct microscopic laryngoscopy was performed under general anaesthesia and deep biopsies were taken from the tumour.

\section{Pathology}

All biopsy specimens taken from the tumour-like lesion showed identical histomorphological features. The cellular tissue showed a predominance of mature plasma cells devoid of atypia, standing out against a background of small lymphocytes, histiocytes/macrophages, polymorphonuclear leucocytes, vessels and loose connective tissue (Figure 3). The overlying squamous epithelium was moderately infiltrated by lymphocytes and plasma cells. Russell bodies and amyloid were not observed. Immunohistochemical reactions with antibodies directed against $k$ and $\lambda$ light chains revealed polyclonality of the plasma cell population (Figure 4a and $b$ ).

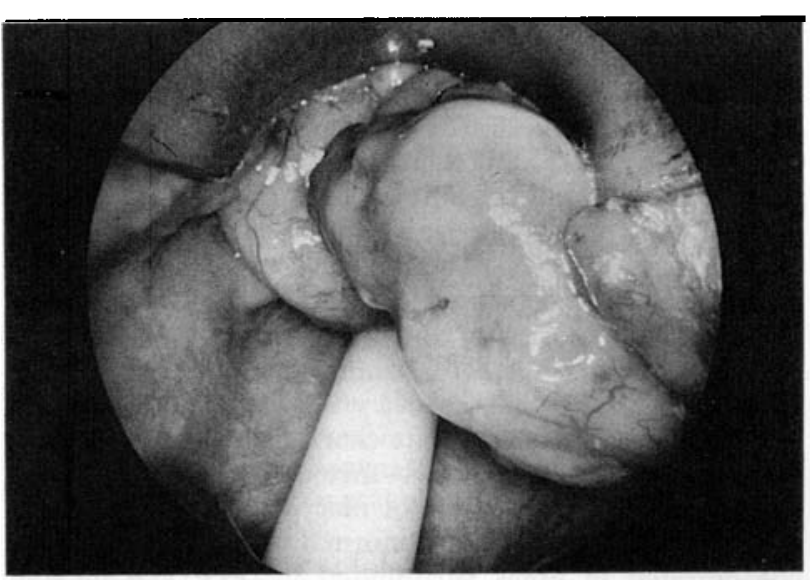

FIG. 1

Endoscopic view of the thickened epiglottis. Intubation tube is seen.

From the Departments of Otorhinolaryngology, Head and Neck Surgery*, Pathology $\dagger$, Radio-Oncology $\ddagger$ and Diagnostic Radiology**, Inselspital, CH-3000 Bern, Switzerland. Accepted publication: 15 May 1995. 


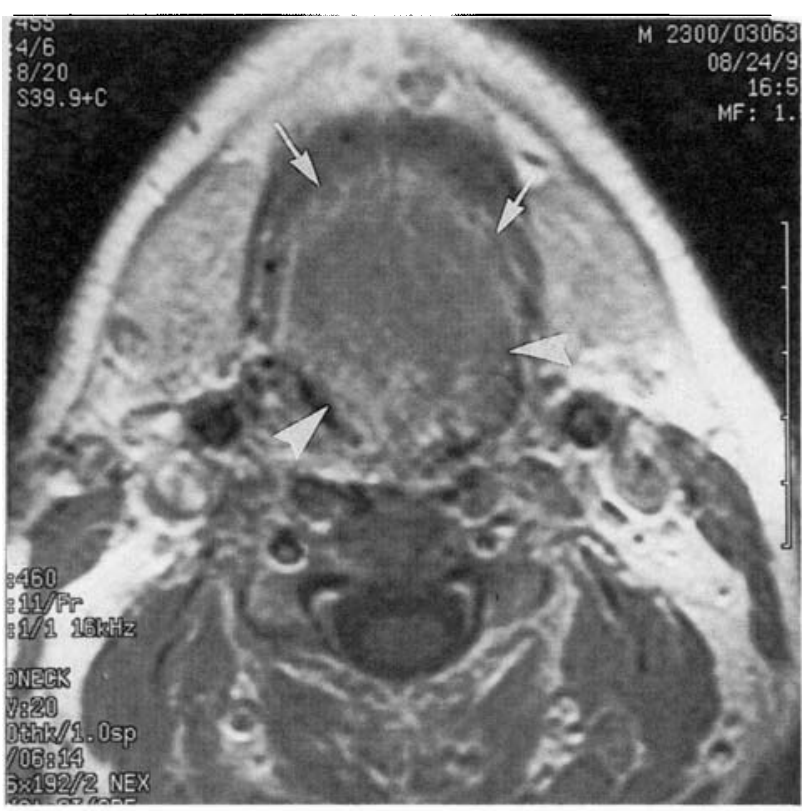

FIG. 2

Axial $\mathrm{T}_{1}$-weighted spin echo sequence obtained after intravenous administration of Gd-DTPA. A large soft tissue mass with minimal contrast enhancement is seen at the level of the epiglottis (arrowheads). The tumour has invaded the valleculae (arrows) and led to near total obstruction of the airway.

\section{Treatment (radiation therapy)}

The patient was treated with parallel opposed Cobalt 60 fields (daily dose $170 \mathrm{cGy}$ (ICRU point); weekly dose 750 cGy). After $2900 \mathrm{cGy}$ (17 fractions) the tumour was still the same size: only after $3400 \mathrm{cGy}$ did the tumour slowly begin to shrink. The total dose given in 30 fractions over 44 days was 5100 cGy. Clinically complete remission was first seen 19 weeks after initiation of radiation therapy.

The patient was followed-up for 15 months without any further symptoms or evidence of recurrence (Figure 5).

\section{Discussion}

The aetiology of plasma cell granuloma is unknown. It is assumed to be of infectious origin (Scully et al., 1982). Bahadori and Liebow (1973) have suggested a hypersensitivity reaction. In our case, no chronic ENT infection was known. In the past, the lesion has been referred to by various names including xanthoma, histiocytoma, xanthomatous pseudotumour, fibrous xanthoma, reflecting the predominant morphological component of the lesion (Scully et al., 1982). The designation of plasma cell granuloma was preferred by Bahadori and Leibow (1973). The majority of the lesions that they describe have mature plasma cells as the predominant cellular component.

The histological features are characterized by polyclonal infiltration of plasma cells mixed with lymphocytes, histiocytes, neutrophils, and/or macrophages. The plasma cells show no cytological abnormalities and are usually concentrated in areas surrounded by well vascularized connective tissue. Russell bodies and amyloid may be present (Shanmugaratnam, 1978; Batsakis, 1983).

The diagnosis is made by histological and immunohistochemical studies. The differential diagnosis must be made from monoclonal neoplastic lesions, such as multiple myeloma and solitary plasmocytoma, a tumour which is likewise a rare neoplasm of the larynx (Zbären and

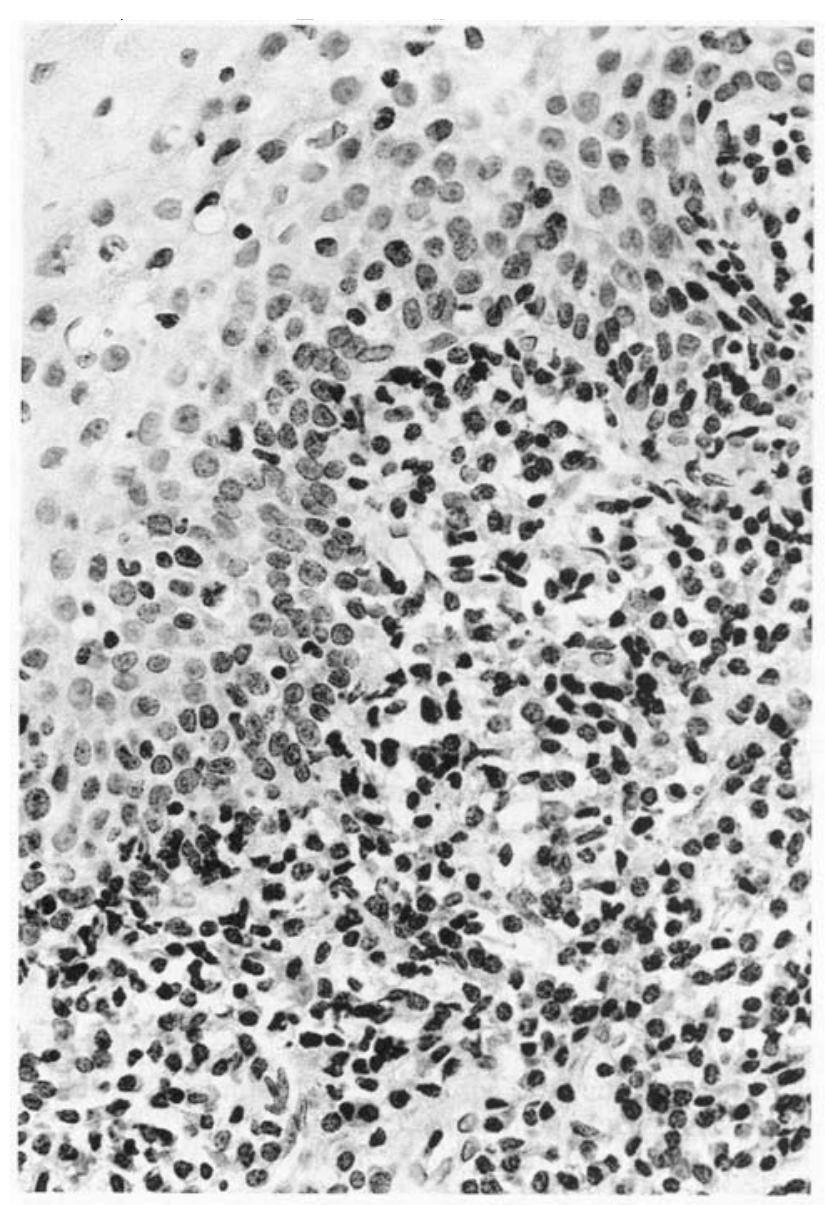

FIG. 3

Fairly dense cellular infiltrate with a predominance of mature plasma cells, standing out against a background of small lymphocytes and histiocytes/macrophages Some plasma cells and lymphocytes are present in the overlying squamous epithelium. (H \& E; × 350).

Zimmermann, 1994). The differentiation between monoclonal and polyclonal infiltration is carried out by immunohistochemical techniques determining the intracellular immunoglobulins.

The standard treatment for plasma cell granuloma is usually surgery (Bahadori and Liebow, 1973; Mandelbaum et al., 1981). In cases where the lesion is locally aggressive and surgically unresectable or resectable with major morbidity, radiation therapy can be an effective alternative (Hoover et al., 1977; Imperato et al.. 1986).

The lesion of our patient was localized in the epiglottis with extension to the valleculae and right aryepiglottic fold, indicating the need for a supraglottic laryngectomy with resection of a part of the tongue base. We thought that such a procedure was not justified and we chose conservative treatment using radiation therapy in spite of the fact that recurrences have been described after radiation therapy (Mehta et al, 1980: Guillemin et al.. 1989).

The two plasma cell granulomas of the larynx described in the literature (Albizzati et al., 1988: Fradis et al., 1988) have been both successfully treated with steroids, but they seem to have been much smaller in size than ours. One patient was followed-up for a period of one year. the other for two years without recurrence. Our patient. treated with radiation therapy has been followed-up for more than one year without recurrence. 

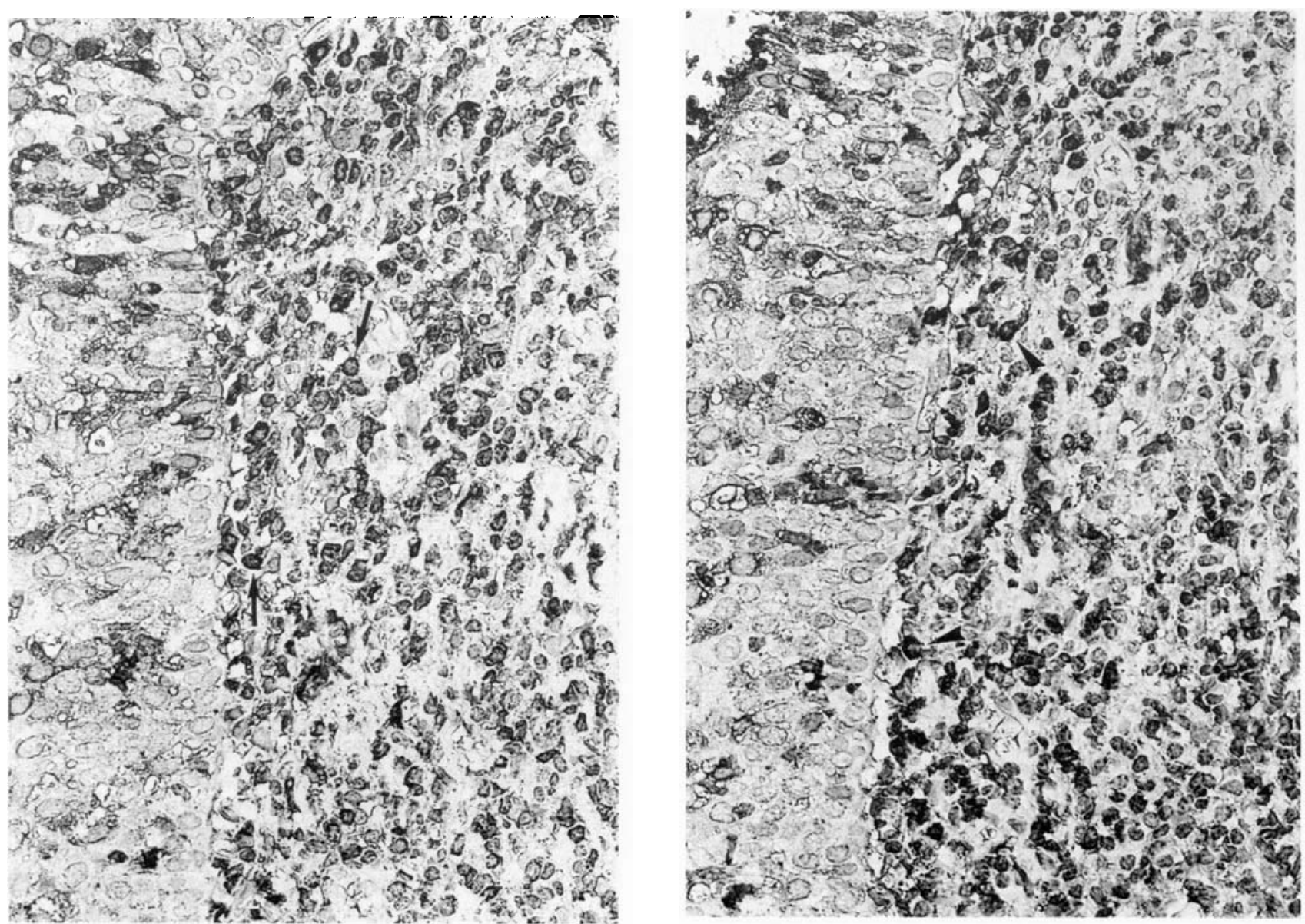

FIG. 4

(a). Dark, stained, mature, plasma cells displaying intracellular $\kappa$ light chains (arrowed). (Avidin biotin technique, peroxidase; haematoxylin as nuclear counterstain; $\times 350$ ). (b). A roughly equal proportion of plasma cells with intracellular $\lambda$ light chains (arrowheads). (Avidin-biotin technique, peroxidase; haematoxylin as nuclear counterstain; $\times 350$ )

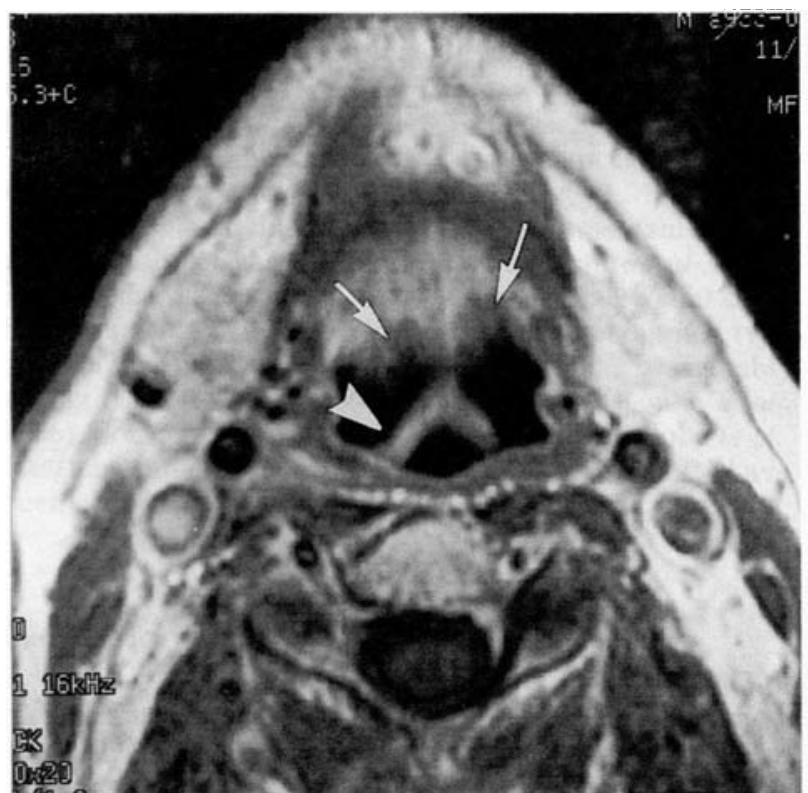

FIG. 5

Axial $T_{1}$-weighted spin echo sequence after intravenous administration of Gd-DTPA obtained 15 months after radiotherapy showing normal appearance of the epiglottis (arrowhead) and the valleculae (arrows)

\section{References}

Albizzati, K. C., Ramesar, R. B., Davis, B. C. (1988) Plasma cell granuloma of the larynx. Journal of Laryngology and Otology 102: 187-189.

Bahadori, M., Liebow, A. A. (1973) Plasma cell granulomas of the lung. Cancer 31: 191-208.

Batsakis, J. G. (1983) Plasma cell tumours of the head and neck. Annals of Otology, Rhinology and Laryngology 92: 311-313.

Fradis, M., Rosenman, D., Podoshin, L., Ben-David, Y. Misslevitch, A. (1988) Steroid therapy for plasma cell granuloma of the larynx. Ear, Nose and Throat Journal 67: 558-564.

Guillemin, Ph., Guillemin, C., Pelte, M. F., Lehmann, W. (1989) Le granulom plasmocytaire dans la sphère ORL. Problèmes Actuels d/Otorhinolaryngologie 13: 358-364.

Hoover, S. V., Granston, A. S., Kach, D. F., Hudson, T. R. (1977) Plasma cell granuloma of the lung, response to radiation therapy. Cancer 39: 123-126.

Hutchins, G. M. Eggleston, J. C. (1979) Unusual representation of pulmonary inflammatory pseudotumor (plasma cell granuloma) as oesophageal obstruction. Journal of Gastroenterology 71: 501-504.

Imperato, J. P., Folkman, J. L., Sagerman, R. H., Cassady, J. R. (1986) Treatment of plasma cell granuloma of the lung with radiation therapy. Cancer 57: 2127-2129.

Issacson, P., Buchanan, R., Mepham, B. L. (1978) Plasma cell granuloma of the stomach. Human Pathology 9: 355-358.

Mandelbaum, I., Brashear, R. E., Hull, M. T. (1981) Surgical treatment and course of pulmonary pseudotumour (plasma cell granuloma). Journal of Thoracic and Cardiovascular Surgery 82: $77--82$. 
Mehta, J., Desphanade, S., Stauffer, J. L., Stanford, R. Fernandez, E. (1980) Plasma cell granuloma of the lung: endobronchial presentation and absence of response to radiation therapy. Southern Medicine 73: 1198-1201.

Monzon, C. M., Gilchrist, G. S., Burgert, E. O., O'Connel, E. J., Telander, R. L., Hoffman, A. D., Li, C. Y. (1982) Plasma cell granuloma of the lung in children. Pediatrics 70: 268-273.

Pack, G. T., Baker, H. W. (1953) Total right hepatic lobectomy. Annals of Surgery 138: 253-258.

Pisciotto, P. T., Gray, G. F., Miller, D. R. (1978) Abdominal plasma cell pseudotumor. Journal of Pediatrics 93: 628-630

Rockford, Y., Linder, J., Schenken, J. R. (1984) Plasma cell granuloma of the thyroid. Human Pathology 18: 848-850.

Scully, R. E., Mark, E. J., McNeely, B. U. (1982) Case records of the Massachusetts General Hospital. New England Journal of Medicine 202: 596-602.

Shanmugaratnam, K. (1978) Histologic Typing of Upper
Respiratory Tract Tumours, World Health Organization Geneva.

Warson, R., Preis, F. A. (1969) New exophytic plasma cell granuloma of the mandible. Report of a case. Journal of Oral Surgery, Oral Medicine, Oral Pathology 28: 791-794.

Zbären, P., Zimmermann, A. (1994) Solitary plasmacytoma of the larynx. Journal of Oto-Rhino-Laryngology and its Related Specialities 57: 49-52.

Address for correspondence:

Dr P. Zbären,

University Clinic of Otorhinolaryngology

Head and Neck Surgery,

Inselspital,

CH-3000 Bern,

Switzerland. 